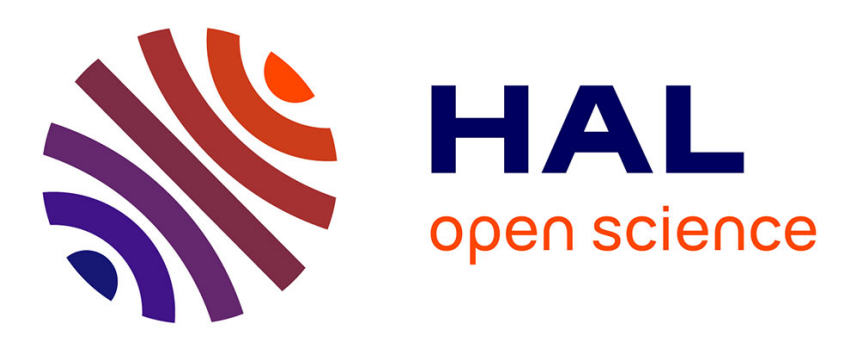

\title{
Beyond average energy consumption in the French residential housing market: A household classification approach
}

Emmanuel Hache, Déborah Leboullenger, Valérie Mignon

\section{- To cite this version:}

Emmanuel Hache, Déborah Leboullenger, Valérie Mignon. Beyond average energy consumption in the French residential housing market: A household classification approach. Energy Policy, 2017, 107, pp.82-95. 10.1016/j.enpol.2017.04.038 . hal-01586597

\section{HAL Id: hal-01586597 \\ https://hal-ifp.archives-ouvertes.fr/hal-01586597}

Submitted on 13 Sep 2017

HAL is a multi-disciplinary open access archive for the deposit and dissemination of scientific research documents, whether they are published or not. The documents may come from teaching and research institutions in France or abroad, or from public or private research centers.
L'archive ouverte pluridisciplinaire $\mathbf{H A L}$, est destinée au dépôt et à la diffusion de documents scientifiques de niveau recherche, publiés ou non, émanant des établissements d'enseignement et de recherche français ou étrangers, des laboratoires publics ou privés. 


\title{
Beyond average energy consumption in the French residential housing market:
}

\section{A household classification approach}

\author{
Emmanuel HACHE ${ }^{a^{*}}$, Déborah LEBOULLENGER ${ }^{a, b, c}$, and Valérie MIGNON ${ }^{b, d}$
}

\section{Highlights}

- We question the heterogeneity of households' energy consumption in the French residential sector.

- We identify the key drivers of households' energy consumption using a clustering method based on CHAID (Chi Square Automatic Interaction Detection) methodology.

- We build an efficient typology of energy-consuming households.

- We identify vulnerable households as well as potential target investors for energy efficiency programs.

\begin{abstract}
In the new environment marked by the growing importance of Green House Gases emissions, fuel poverty and energy efficiency in the different national agendas, the comprehension of energy demand factors appears to be crucial for the effectiveness of energy policies. We consider these latter could be improved by targeting specific households' groups rather than searching to follow a single energy consumption level target. This article explores the scope of having a disaggregated energy consumption market to design policies aimed at curbing residential energy consumption or lowering its carbon intensity. Using a clustering method based on CHAID (Chi Square Automatic Interaction Detection) methodology, we find that the different levels of energy consumption in the French residential sector are related to socio-economic, dwelling and regional characteristics. Then, we build a typology of energy-consuming households where targeted groups (fuel poor, high income and high consuming households) are clearly and separately identified through a simple and transparent set of characteristics. This classification represents an efficient tool for energy efficiency programs and energy poverty policies but also for potential investors, which could provide specific and tailor made financial tools for the different groups of consumers. Furthermore, our approach is helpful to design an energy efficiency score that could reduce the rebound effect uncertainty for each identified household group.
\end{abstract}

Keywords: Energy consumption, residential sector, clustering method, France. JEL Classification: Q48, I32, C38.

\footnotetext{
- We are grateful to Alain Tourdjman for insightful comments and suggestions. Any remaining errors are ours. The views expressed in this paper are those of the authors and do not necessarily reflect those of IFP Énergies Nouvelles, EconomiX, or BPCE-SA.

${ }^{a}$ IFP Énergies Nouvelles, 1-4 av. de Bois Préau, F-92852 Rueil-Malmaison, France.

* Corresponding author. Tel.: +33 1475267 49; email: emmanuel.hache@ifpen.fr.

${ }^{\mathrm{b}}$ EconomiX - CNRS, University of Paris Ouest, France.

${ }^{\mathrm{c}}$ BPCE-SA, Paris, France.

${ }^{\mathrm{d}}$ CEPII, Paris, France.
} 


\section{Introduction}

Residential and tertiary sector represents about $45 \%$ of global energy consumption in France and $21 \%$ of $\mathrm{CO}_{2}$ emissions in 2012. This sector consumes more energy than any other sector in the country (31\% for transport, $21 \%$ for industry, and less than $3 \%$ for agriculture) and within the sector, the residential part accounts for $60 \%$. The residential sector is then considered as a key driver for energy efficiency programs — such as insulation — and more generally for energy policy. Energy consumption in private houses stems from three main usages: space heating (70\% of the total expenditures), hot water and cooking $(15 \%)$ and specific electricity use ${ }^{1}(15 \%)$. Moreover, the promotion for energy efficiency in residential building is mainly based on conventional and modeled consumption ${ }^{2}$ that does not take into account thoroughly and narrowly the households' characteristics and the effective behaviors in order to offer a comparable set of energy efficiency measures on buildings.

Table 1. Descriptive statistics depending on households' characteristics, dwelling type and heating technology in 2006

\begin{tabular}{llccccc}
\hline \multirow{5}{*}{ Houses } & $\begin{array}{c}\text { Observation } \\
\text { number }\end{array}$ & $\begin{array}{c}\text { Energy } \\
\text { annual } \\
\text { expenditures }\end{array}$ & $\begin{array}{c}\text { Annual } \\
\text { global } \\
\text { income }\end{array}$ & $\begin{array}{c}\text { Energy } \\
\text { budget } \\
\text { share }\end{array}$ & $\begin{array}{c}\text { Energy } \\
\text { expenditures } \\
\text { per person }\end{array}$ \\
\cline { 2 - 7 } & $\begin{array}{l}\text { Electricity } \\
\text { Heated }\end{array}$ & 5298 & $1250.00 €$ & $30506.50 €$ & $4.01 \%$ & $475.00 €$ \\
\cline { 2 - 7 } & $\begin{array}{l}\text { Median } \\
\text { Houses }\end{array}$ & 20661 & $1200.00 €$ & $27720.00 €$ & $4.25 \%$ & $447.00 €$ \\
\hline \multirow{2}{*}{ Flats } & $\begin{array}{l}\text { Gas } \\
\text { Heated }\end{array}$ & 6695 & $700.00 €$ & $19063.00 €$ & $3.51 \%$ & $334.67 €$ \\
\cline { 2 - 7 } & $\begin{array}{l}\text { Electricity } \\
\text { Heated }\end{array}$ & 4137 & $709.00 €$ & $16710.00 €$ & $4.05 \%$ & $403.00 €$ \\
\cline { 2 - 7 } Median & 17482 & $600.00 €$ & $18020.00 €$ & $3.33 \%$ & $300.00 €$ \\
\hline Tlats & 38143 & $891.00 €$ & $22722.00 €$ & $3.75 \%$ & $385.00 €$ \\
\hline
\end{tabular}

\footnotetext{
${ }^{1}$ This usage is growing at a very high rate as households and houses are more and more connected, and the appliances evolve toward high technology and multimedia services.

${ }^{2}$ See French Environment and Energy Management Agency.
} 
A cross-tabulated analysis enlightens us on the heterogeneity and variability of French households' energy consumption given dwelling types, but also income and other households' characteristics and location choice (urban versus rural zones). ${ }^{3}$ The annual energy bill differs greatly whether the household in collective dwellings can have access to a gas infrastructure or not. In fact, in the case of flats, gas-heated households appear to have a lighter annual global energy bill, but also a lighter energy budget share (Table 1). It is also worth noticed that gas-heated households have a higher annual income than average and electrically-heated households.

Specifically, our aim in this paper is to address this question of heterogeneity in energy consumption in France by relying on a disaggregated-level analysis. In this regard, household group classification can be useful to tackle the rebound effect and the nonlinear demand for energy services. The "take-back" or "rebound effect" energy services with a corresponding decrease in the effective price, the size of which depends upon the underlying cost structure (Greening et al., 2000). When energy efficiency measures do not take into account the gap between expected and actual consumptions, they might face some rebound effect. It has been observed in the transportation sector and also in the residential one. Regarding space heating for example, the estimated rebound effect in the economic literature ranges from 10\% to 30\% (Dubin et al., 1986; Greening et al., 2000). Then, the rebound effect highlights the importance of getting detailed information on household revenue level or income path. The total income sets a budget constraint that drives directly the quantity of energy service consumed and its evolution with price and income path via demand elasticity. In addition, it determines the implicit discount rate at which households make investment decisions for equipment (Hausman, 1979) or energy efficiency strategies

\footnotetext{
${ }^{3}$ See Table 1.

4 The rebound effect—also called the "Jevons Paradox"—was highlighted in 1865 by William Stanley Jevons within its famous book entitled "The Call question". This ecological paradox describes the non-expected consequences in terms of natural resources consumption resulting from a refinement of a technological process. Thereby the implementation of an improved technology through a more efficient energy process can paradoxically lead to an increase in energy consumption. The widespread use of the technology, the diminution of the incentives to rationalize energy consumption, the decrease in unit price for energy services and the revenue effect observed through energy efficiency gains can explain the rebound effect (Khazzoom, 1980).
} 
(Hasset and Metcalf, 1993). In France, energy efficiency programs exist for example for modest and old landlords in olds dwellings (National Housing Agency programs), but there is no specific policy for the other groups. Wide-ranging policies are preferred such as subvention for energy efficiency financing (zero interest rate loans) or tax cuts (tax credit for sustainable development and tax credit for energy transition).

The rebound effect can take two forms. The direct rebound effect is when households decide to consume more of the energy service after a decrease in price created by the household reallocation of the extra revenue to more comfort or other energy services. The indirect rebound effect is when households dedicate their extra revenue to the consumption of other goods, services and factors of production that also require energy for their provision (Khazzoom, 1980). As for some empirical estimates, recent studies have shown that the rebound effect varies whether the substituted service is low-carbon intensive (estimated rebound in the UK of $12 \%)$, "behavior as usual" (34\% rebound) or carbon intensive. The latter case even produces backfire effect (Druckman, 2011). Empirical literature usually relies on the price elasticity to measure the direct rebound effect, but Sorrell and Dimitropulos (2008) argue that this method, whether it is used on cross-sectional or historical variation, can lead to overestimation of the rebound. This overestimation is notably due to asymmetry in energy elasticities' estimates and collinearity (Baker and Blundell, 1991). Being aware of these methodological problems, we go further from the previous literature and derive energy consumption from the classification of household groups. Group specification indeed overcomes the nonlinear and collinear relationship between demand and income, and provides a solid outline regarding shifts of the Engel curves ${ }^{5}$ according to demographics and household groups.

Disaggregated demand analysis allows us to tackle the issue related to the measures and indicators of fuel poverty in residential housing. In the UK, $80 \%$ of the 4 million fuel poor are also vulnerable households (Department of Energy and Climate Change; DECC, 2009). The latter can be divided in three categories: low revenue (below $60 \%$ of the median income), elderly, allocation benefit households and single parents. Every group has an increased

\footnotetext{
${ }^{5}$ Engel curve describes how a consumer's purchases of a good like food varies as the consumer's total resources such as income or total expenditures vary. Engel curves may also depend on demographic variables and other consumer characteristics. A good's Engel curve determines its income elasticity, and hence allows us to classify the good as inferior, normal, or luxury depending on whether the income elasticity is respectively negative, inferior to unity or greater than unity.
} 
vulnerability to fuel price as corresponding households spend a larger amount of their revenue on energy bills (Hills, 2012). Each group also has very heterogeneous energy consumption habits (Jamasb and Meier, 2011). The main factor that triggers or identifies fuel poverty in Europe is the housing location, the region's climate playing a key role in the ability to adequately heat a home along with residing in a rural area followed by residing in an intermediate area of urbanization (Thomson and Snell, 2013). While there are on average similitudes in the fuel poverty rate between rural and urban households, the impact of specific dwelling and sociodemographic aspects combined reveals critical differences. Although urban households are more likely to spend more time in fuel poverty, rural households are expected to fall into worsened levels of fuel poverty (Hills, 2012), and are more vulnerable to fuel prices especially when they live in private rental accommodations (Roberts et al., 2015).

As stressed above, our aim in this paper is to account for heterogeneity in energy consumption by relying on a disaggregated energy consumption analysis of the French households. Our contribution to the existing literature is threefold. First, while the bulk of the empirical literature is based on microeconomic tools as price elasticity, we rely on a clustering approach - the Chi Square Automatic Interaction Detection (CHAID) approach — allowing us to identify the main drivers of households' energy consumption. Second, we propose a detailed typology of households based on a transparent set of characteristics. Third, thanks to our classification, we provide recommendations to improve energy efficiency programs by giving more appropriate and detailed information on the residential housing market than the usual simple average household energy consumption analysis.

The rest of the paper is organized as follows. Section 2 briefly reviews the existing literature. The data and methodology are described in Section 3. Section 4 presents our main results and related comments, while Section 5 summarizes our findings and provides policy recommendations.

\section{Review of literature}

Energy demand is a latent variable derived from a set of characteristics that can be divided in three types: household characteristics (such as income, family type, living habits or comfort 
needs), dwelling characteristics (such as size and type), and exogenous factors such as the local energy mix (especially whether households have access to city gas or not). Let us now survey the economic literature on these different issues in three main themes.

\section{Income and prices}

There are as many demand elasticities in the space heating demand as there are different types of fuel available. In addition, income and price elasticities change with both time and income levels. As a normal good, an increase in energy prices should trigger a reduction in households' energy demand level by using less energy services (they can lower the temperature at home) or substituting other inputs for energy and choosing less energyintensive appliances or even homes. While the first arbitrage can be realized in the very short run, the second one requires a sharp investment in capital and is only possible in the medium term (new heating system) or in the long run (change location and home). The relationship between budget share and income has several shortcomings (Blundell et al., 2014): demands for commodity are nonlinear with income and Engel curve is well known to differ by demographic type across households. Using a panel data modeling, Jamasb and Meier (2010) find that the energy consumption behavior of UK households heavily depends on income level. The authors describe the Engel revenue path for households' energy consumption to be slightly S-shaped. Energy spending globally increase with income, but its magnitude augments accordingly to income thresholds as it reflects the changing nature of consumption of energy, electricity, and gas when income changes. Energy is used for necessity needs at low income levels and is enriched for higher incomes (Meier et al., 2013).

Income level could also be considered as a proxy for assessing a specific degree of comfort and the intensity factor among households. As income rises, households tend to exhibit preferences for less energy-intensive housing and appliances as they do not want to sacrifice any comfort in an energy price increase context. In recent French and UK studies (Druckman and Jackson, 2008; Cayla et al., 2011), the relation between income and comfort level describes a factor 2 difference between the levels of comfort for the $10 \%$ poorest and the $10 \%$ richest households. In fact, the gap between expected and real consumption can reach up to a $65 \%$ overestimation of energy consumption compared to a model including intensity factor which is mainly driven by energy budget share, behavioral factors (elasticities and rebound 
effect), and non-standardized space heating management (Cayla et al., 2010). The consecutive actual over normative ratio is used to measure a level of comfort that approaches the notion of service factor developed by Haas and Biermayr (2000).

\section{Households' characteristics}

Other socio-economical characteristics play a major role in the actual energy consumption in residential building. Households'characteristics appear to influence at least 33\% of energy consumption variations (Sonderegger, 1977; Cayla et al., 2010), among which household's tenure and composition are two major ones. The effect of occupant characteristics might be larger than expected, since they determine the type of dwelling (Guerra Santin et al., 2009). The presence of learning effect toward more efficient energy use is also important, although results regarding the effect of age are not clear cut in the literature, being sometimes significantly associated (Meier and Rehdanz, 2010) and sometimes less obviously associated with different levels of energy consumption (Wyatt, 2013). The size of the household and its composition influence the choice of the heating system type. Family size is negatively related with electric heating (Vaage, 2000; Braun, 2010). This latter is more suitable for small and active households who tend to spend less time at home. Household tenure is also playing a significant role. Ownership lowers the energy price vulnerability as households who own their housing are more likely to have more energy efficient houses (Rehdanz, 2007). Property owners and tenants react differently to income and energy prices changes (Meier and Rehdanz, 2010). Level of comfort is also a key explanation when investigating the elderly and more vulnerable household groups. Indeed, elderly people, but also families with small children, require an increased level of comfort that might trigger higher levels of energy consumption (Meier and Rehdanz, 2010). On the other hand, very poor households can use comfort as an income arbitrage: they choose less energy expenditures but a decreased level of comfort (low room temperature or fewer heated surface) (Devalière et al., 2011).

\section{Dwelling type and regional characteristics}

Dwelling characteristics are also major factors: the age, the size and floor area of the housing play a significant role as well as its degree of detachment that increases the energy use (up to dwelling of $100 \mathrm{~m}^{2}$ ) (Wyatt, 2013). The impact of the dwelling type reveals in many studies 
the strong correlation between dwelling characteristics, income and tenure. Owners tend to live in detached or semi-detached houses, whereas flats are mainly rented. As such, if heating expenditures are mainly due to differences in the types of dwelling, comparing owner and renter heating expenditures for one type of dwelling (flats or houses) does not always lead to different results (Meier and Rehdanz, 2010). Regional and geographic location can play a significant role; for example, there is a gap between East and West Germany (Braun, 2010) or rural and urban households in the UK (Roberts et al., 2015). The fact that households live in a cold area leads to higher heating expenditures, regardless of the weather because those households have a better heating equipment and they experience an increased level of comfort during cold days (Meier and Rehdanz, 2010; Cavailhès et al., 2011).

Why do we need a segmentation analysis for energy expenditures in the residential housing market? Studies that analyze energy consumption at an individual level basis are usually of two types: discrete (demand for appliances) or continuous (demand for the energy itself) models, or conditional demand. ${ }^{6}$ Another approach to energy demand modeling is to specify the average relationship between energy expenditures and households' characteristics as nonlinear and assign an energy expenditure level probability to a homogenized household group where each agent within the group is supposed to have the same energy consumption level. Analyzing the relationship between income and domestic fuel use, Druckman and Jackson (2008) compare the results for two levels of regional disaggregation (national and local) and different types of households by using the Local Area Resource Analysis (LARA) model. In this study, household groups segmentation comes directly from the Output Area Classification constructed by Vickers and Rees (2007) based on geographic and socioeconomic characteristics. They highlight the relevance of a disaggregated approach, evidencing many groups with specific energy consumption habits showing that: (i) households in cities spend the lowest proportion of disposable income on fuels, and (ii) "City Living" but also "Typical Traits and Prospering Suburbs" are groups that may be called "fuel rich" as they spend the lowest share of their income in fuel, their long-run price elasticity of demand being therefore inelastic. Following the same motivation and relying on a clustering method, the Centre for Sustainable Energy OFGEM program (2014) finds a total of 12 energy

\footnotetext{
${ }^{6}$ For discrete and continuous models, see, e.g., Dubin and McFadden (1984) on US data, and Nesbakken (2001) on Norwegian data. Turning to the conditional demand approach, see Parti and Parti (1980) for the US, Baker et al. (1989) and Meier and Rehdanz (2010) for the UK, and Redhanz (2007) for Germany.
} 
consumer archetypes regarding gas and electricity consumption for UK households in 2010 and 2014 with the following influencing characteristics: heating fuel, income, household type, region, tenure and urban density - the set of predictors differing for gas and electricity consumption.

\section{Data and methodology}

\subsection{Data}

We rely on individual household-level data extracted from the 2006 housing survey conducted by the French national statistics bureau ${ }^{7}$ on households in their housing. The survey describes the income, housing characteristics and energy consumption habits of 42963 French households. Although the number of observations is rich enough to describe accurately the French households' energy and housing habits, there exists an acknowledged bias that underestimates the poorest section of the population that is trickier to include in such national survey (data collection issue). Also, energy expenditures are only reported for households with individual heating (i.e., $90 \%$ of the landlords' population, but only $64 \%$ of the tenants) as energy detailed expenses are more identifiable. After clearing the data, we lose 4820 observations, i.e. $11 \%$ of the original dataset.

We consider three types of variables of interest: energy expenditures, energy budget share and global income all measured annually (see Tables 1 and 2, and Appendix 7.1 for detailed descriptive statistics). As for explanatory variables, space heating consumption is a well behaved proxy for short-term elastic residential consumption. Indeed, it accounts for $70 \%$ of the residential energy demand and offers a handy flexibility that helps capture consumption variations across households as we frequently observe a 10-30\% rebound effect (Greening et al., 2000). We also focus on the energy budget share because we consider it as a good measure of fuel poverty. We analyze energy spending, elasticities and expenditures distribution across homogeneous groups of households and propose another indicator for fuel vulnerability and poverty.

\footnotetext{
${ }^{7}$ The detailed results of the housing survey can be found on the website of the National Institute of Statistics and Economic Studies (INSEE) : http://www.insee.fr/en/default.asp
} 


\subsection{Methodology: CHAID method}

We use the Chi Square Automatic Interaction Detection (CHAID) method ${ }^{8}$ developed by Kass (1980) to analyze the annual energy consumption of French households in the residential sector. The CHAID method stems from the popular data mining technique AID (Automatic Interaction Detection) and is mostly used in survey datasets for segmentation analysis. This technique of tree growing - also known as "hierarchical splitting", "partitioning", "group dividing" or "segmentation" - is widely used in strategic marketing for partitioning data into homogeneous groups in terms of the response variable. ${ }^{9}$ Its aim is not necessarily to improve the prediction power of a linear regression, but to gain better knowledge on how the variables of interest are linked to the explanatory variables beyond the restricted additive influence. ${ }^{10} \mathrm{In}$ our case, we want to test whether our understanding of the French households' energy consumption and expenditures in the residential sector is improved when using disaggregated prism rather than an average national measure.

The different phases of the methodology are sequenced as follows:

1. We determine the key predictors of mean and median energy consumption levels. They might be socio-demographic or dwelling characteristics and localization, or exogenous factors such as climate and unobserved effects. To this end, we use both Multiple Correspondence Analysis (MCA) and logistic regression.

2. We implement the CHAID method to hierarchize and group energy consumption levels with respect to the key predictors in order to start a households' typology regarding their energy consumption.

\footnotetext{
${ }^{8}$ See Appendix 7.2 for a summarized description.

${ }^{9}$ First tree growing methods have been identified by Belson (1959), and Morgan and Sonquist (1963). The AID algorithm is a binary regression on a quantitative variable which is the most popular "group dividing" data mining technique. It has been enriched for (i) categorical outcome using a so-called theta criterion (THAID or Theta-AID) thanks to Messenger and Mandell (1972) and Morgan and Messenger (1973), and (ii) for multivariate quantitative outcome variable (MAID).

10 "Particularly in the social sciences, there are two powerful reasons for believing that it is a mistake to assume that the various influences are additive. In the first place, there are already many instances known of powerful interaction effects advanced education helps a man more than it does a woman when it comes to making money, [...] Second, the measured classifications are only proxies for more than one construct. [...] We may have interaction effects not because the world is full of interactions, but because our variables have to interact to produce the theoretical constructs that really matter." (Morgan and Sonquist, 1963).
} 
3. We test the value of emerging archetypes (changing the dependent variable and/or key predictor variables).

4. We feed the archetypes into the complete dataset and enrich the profile analysis (with frequency and MCA-based tests).

5. We analyze specified groups (coupling key leverages for successful efficiency programs) and present the findings and policy implications.

It is worth mentioning that the predictors are allowed in the method to be either monotonic (relying on an ordinal scale) or free (purely nominal) as in AID, but the main novelty is the development of a floating predictor. The latter allows one category of an ordinal variable to have an unattributed ergo unknown position on the ordinal scale, which is highly convenient when dealing with a missing category which is frequent with microeconomic survey data. The CHAID technique aims at maximizing the homogeneity of each group by means of purity measures using a floating predictor which has been proved to be most useful in microeconometrics.

Let us now briefly compare the CHAID approach with the main other techniques. Consider first AID-based methods. Ritschard (2010) describes two CHAID features that contribute to its popularity. First, CHAID selects the predictors on the basis of the optimal split each potential predictor would produce at each node (continual significance). Whereas AID selects the "most explanatory" split, CHAID would rather choose the "most significant" one. Second, CHAID uses p-values with a Bonferroni correction as splitting criteria. It is a statistical significance test that accounts for multiple testing. There exist other decision-tree methods like THAID or MAID; the main difference lies in the definition and parameterization of the splitting criteria: residual sum of squares (RSS, or "within" sum of squares) for AID, generalized RSS for MAID, theta for THAID, and Fisher or its Chi-square approximation significance test ( $p$-values with a Bonferroni correction) for CHAID.

Second, unlike the CART (Classification And Regression Tree) method, the CHAID analysis does not allow for continuous variables in the model. It therefore exposes the analyst that 
arbitrary splits a continuous variable himself to misspecification costs, but this argument is weak when the chosen categories for a continuous variable are of value themselves. For instance, when we split energy consumption in deciles, we allow for an easier comparison with other relevant decile categories like revenue or budget. Comparing CART and CHAID analyses, Haughton and Oulabi (1993) found that the two models yield very close results and highlight three main conclusions. Firstly, CHAID model is much more easy and accessible to run with a personal computer. Secondly, CART method is preferable if the model has a very large number of explanatory variables (more than 600), but it is not our case. Finally, when dealing with missing variables, CART is of great advantage when they appear for a continuous variable, but CHAID is preferable when the missing observations are of special significance to the response variable. If the latter is confirmed, one must create a special category of missing values when using CHAID. Overall, given their quite similar performance (despite different statistical techniques), one will use (i) CART if the dataset contains many continuous variables, and (ii) CHAID for datasets with fewer and categorical explanatory variables, as in our case.

Finally, the third main approach is the logistic regression (McCarty and Hastak, 2007) which provides a response probability on a dichotomous variable. Decision trees segment the dataset into homogeneous groups of people according to a categorical (CHAID) or continuous (CART) variable, the first one being privileged for its predictive power and the latter for its explicative power. Furthermore, as our variable of interest is richer when divided in decile rather than binomial, the CHAID method is preferable. Last but not least, the CHAID method, unlike the logistic approach, is distribution free. It means that it allows the relationship between the explanatory variables and the response variable to be non-monotonic (curvilinear for instance).

Despite its various advantages, four main limits of the CHAID methodology have to be mentioned. First, due to a heuristic approach, the model does not guarantee optimality since it is a forward stepwise method: once a variable is chosen, it cannot be eliminated in a later stage (Van Diepen and Franses, 2006). Hence the trees cannot determine the global importance of each factor. We overcome this limit by running a previous multiple correspondence analysis (MCA) and global significance tests (Fisher) on GLS regressions to select explanatory variables that are globally and individually significant. Second, the tree 
instability raises two issues. On the one hand, the segments derived by CHAID differ significantly with respect to the criterion. On the other hand, the decision tree stems from random iteration tests and the results (number and criteria selection) can vary when the same model is implemented to another dataset. Consequently, if the original data are replaced with a fresh sample, a different tree may emerge with different splitting rules. In our case, a different CHAID tree for the 2012 housing survey dataset is detrimental, but not catastrophic because it can provide information on a new segmentation that explains new energy consumption behaviors and attests that they have dramatically changed between 2006 and 2012. ${ }^{11}$ Third, CHAID analysis may encounter over-fitting problems: the predictions of the response variable could be worse than with no model, even if the CHAID tree fits the dataset well. However, this issue can be relativized in our case as we are looking for a way to target households in an existing dataset and to explain energy consumption rather than predict it. Finally, the CHAID method is mainly intended for large samples (min 1000 cases; Doyle, 1973). The approach uses the Chi-Square test of independence and therefore assumes that the variables follow a chi-square distribution, a property which is asymptotically verified in large samples such as in our case. On the whole, all those afore mentioned issues are overcome in our analysis, thanks to our methodology and the properties of our dataset.

\section{Results}

We first describe (Section 4.1) the identified groups resulting from the implementation of the CHAID algorithm and analyze the segmenting variables that feed the model before focusing (Section 4.2) on two selected pen portraits: the fuel poor households and the "high income high energy-consuming" households. Then (Section 4.3), we display the groups in a twodimension plan in order to realize market segmentation for residential housing. This method highlights potential rebound or back-fire effects as well as windfall effects. Finally (Section 4.4), we investigate the benefits for using a scoring method in order to reduce ex post uncertainty for energy efficiency investment.

\footnotetext{
${ }^{11}$ The next housing survey of the French National Institute of Statistics and Economic Studies (INSEE) should be published in 2016.
} 


\subsection{Cluster tree}

We investigate French households' global and heating energy annual expenditures, considering a vector of statistically tested ${ }^{12}$ variables of three kinds: household's income and characteristics, dwelling type and heating main technology, and localization features. Our first-step results highlight that the CHAID algorithm separates the households regarding their dwelling type. This result is not surprising because the average energy expenditures double in houses compared to collective dwellings. It also captures most of the variations due to the difference in the dwelling size. Then, the algorithm divides the groups regarding their main heating input between gas, electricity, liquid fuel, coal, wood and other type (see Table 1). We then focus on four main family groups.

Households that live in houses or flats and consume electricity or gas to heat their homes in France account for two third of the heating fuel mix (see Table 2). In a second step, the CHAID algorithm then separates households within these four families into sub-groups of various sizes that are supposed to consume their respective heating fuel homogeneously.

Table 2. Residential heating fuel type per dwelling type

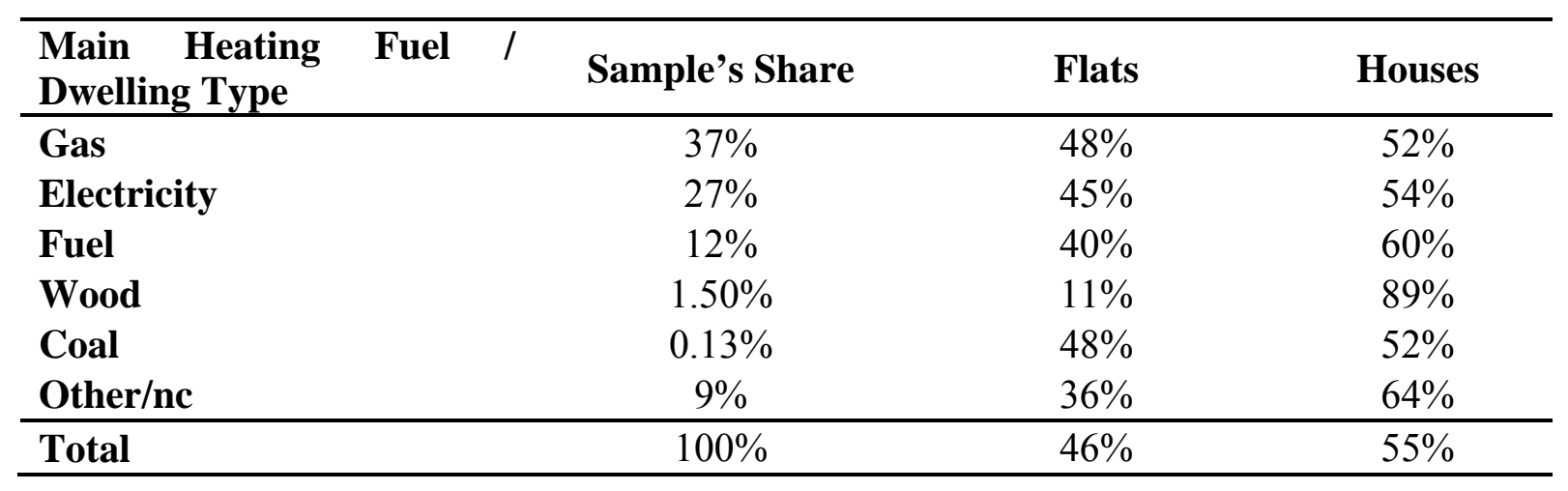

Source: Authors' results.

\footnotetext{
${ }^{12}$ We rely on an ordered logit model to test the goodness of fit of the clustering variables
} 
Figure 1. Final CHAID segmentation tree for French households' energy consumption

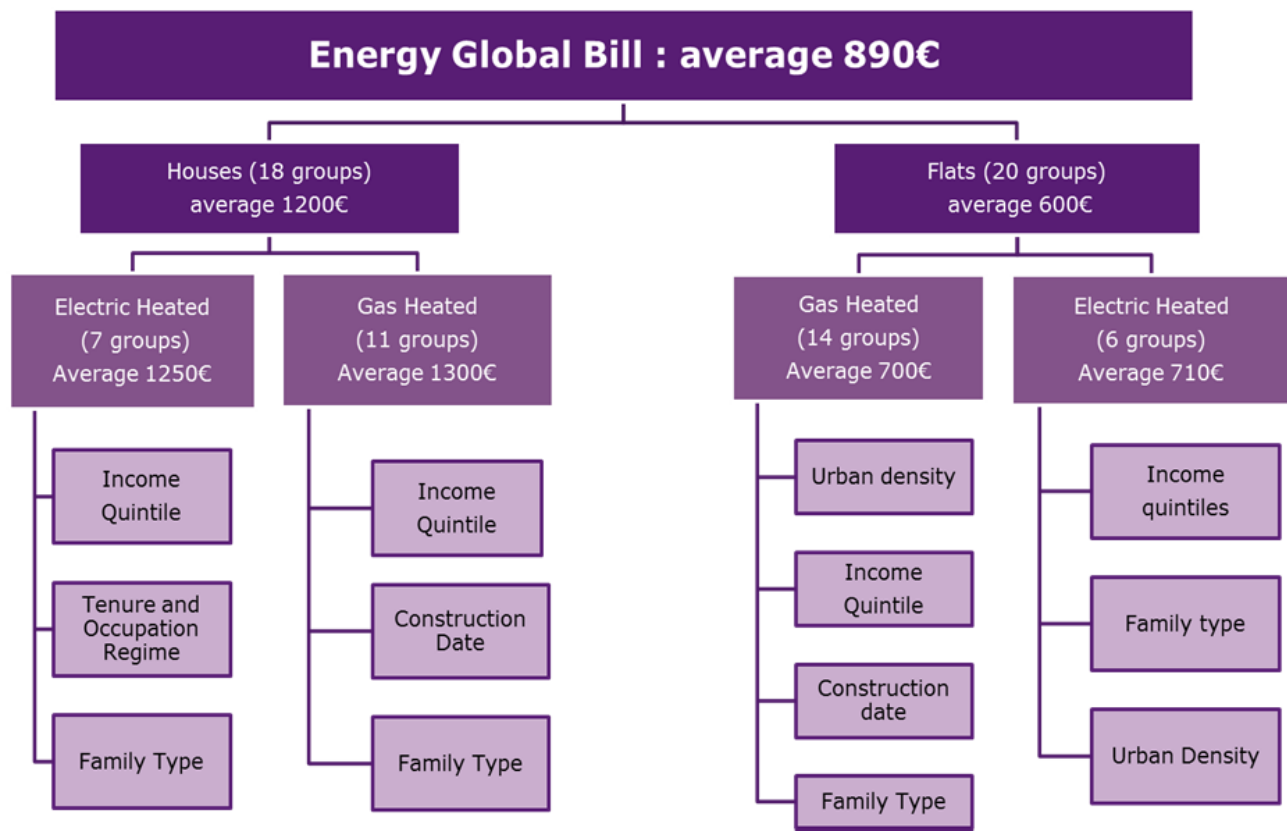

Source: Authors' results.

Our analysis leads to identify 18 sub-groups in houses and 20 sub-groups for flat housing (Figure 1). Income quintile appears to be the first segmentation node in three of the main groups out of four, which confirms the strong relationship between income and energy consumption even in a nonlinear approach. The household's family type is also a splitting factor in every main group but at different levels of the tree. It is rather straightforward as the number of active occupants (couple with children or no child, single parent or person) in the household determines the gap between the global budget and the level of heating space required but also the level of comfort needed.

In flats, households (income and family type), dwelling (construction date) and location (urban density) characteristics play a significant role in explaining different levels of energy expenses across households. In gas-heated flats where income appears to be the second node, urban density plays a major role in gas expenses levels. Indeed, gas-heated flats are fueled by collective systems and the access to a gas infrastructure is crucial but unequally distributed between dense cities and more rural areas. 
It is also worth mentioning that the construction date is a key splitting factor only for gasheated groups. One explanation may rely on the global age of the house or flat that determines also the technology of the heating system when it is gas fueled as it is part of the building infrastructure, whereas electric heating is more used as flexible equipment and is not necessarily attached to walls.

Finally, tenure and occupation regime only appears to be a significant node in electric-heated houses. In our group analysis, it is one of the key factors to identify fuel poverty in houses, as we observe that there is a fuel poverty group (hitting the $10 \%$ effort rate) among rented electric-heated houses.

\subsection{Pen portraits}

We chose a selected few key groups to identify the different leverages of action or policy measures that fit each group best. Each CHAID resulting group is analyzed through its median global energy bill, income, electricity and gas expenditures and its energy effort rate. The first household groups that drive our interest are those with a median energy effort that flirt with the fuel poverty rate of $10 \%$. Two groups are in this case, representing $10.5 \%$ of the total group population and $3.2 \%$ of the whole survey sample. Those are gas- or electricityheated households living in houses (there was no electricity-heated households with energy share close to the $10 \%$ threshold $^{13}$ ), their bear an energy share of above $9.50 \%$ although they have a median annual energy expenditure of $1200 €$ which is the population median level in houses. What makes them fuel poor is that they have a very low income and both groups belong to the first revenue quartile, putting them together as an energy spending group in the first place. They live in medium size houses (between 60 and $\left.100 \mathrm{~m}^{2}\right)$ but old $(50-100$ years old houses) for the gas-heated group. Those groups are mostly old couples, being more than 50 years old, for $70 \%$ of the fuel poor group or single parents. Most of them are owners (which is reasonable to say vis-à-vis the tenure distribution between houses and flats) but electricity-heated groups are tenants, confirming the importance of the tenure status for this main group. Those groups are defined out of the energy efficiency market and are clearly a target for public policy measures and help.

\footnotetext{
${ }^{13}$ Note that this finding does not mean that fuel poverty does not exist in flats, but it is probably hidden by an intensity and/or an intermittence factor.
} 
At the opposite, the second group of interest corresponds to "High Income High Consumption" (HIHC) households that could feed a spawning energy efficiency market for private housing. In other words, these are households with high energy expenditures but also high income and the lowest energy share, making them receptive and financially capable of enacting energy efficiency measures on their homes (households' groups that are in the market). We identify four household groups (31\% in houses and $7 \%$ in flats) who represent $11 \%$ of the whole survey sample. If we focus our interest on households living in flats, we find that their have very low energy effort rate relative to their peers $(1.55 \%-1.65 \%)$ that is due to a very high income (HIHC groups belong to the highest income quintile). They also have energy expenditures above the average in flats, that is $850-875 €$ (vs. 600€). They live in middle to high urban density (gas group) and have big flats: $60-100 \mathrm{~m}^{2}(60 \%)$. They are couple or single parent, no children (electricity group), white collars or intermediate professions.

\subsection{Market mapping}

This section is an attempt to drive the attention on the energy policies that can produce mixed results on each households' group whether they are targeting fuel poverty, energy efficiency or energy savings. Figures 2 and 3 represent our households' groups dispatched on an income versus global energy expenditure plan with indication of their weight in the sample: the bigger the bubble, the bigger the group in population size (numerical figures are shown in Appendix 7.3). This projection allows us to separate more clearly the groups with respect to an intensity effect (how far are the household's energy expenditures from the median) and a revenue effect (how far is the household's annual income from the median). These figures give a visual perspective on the energy policy incentive and potential effects on each group, and emphasize the importance of having a disaggregated-group approach regarding energy policy measures.

The energy efficiency market can be divided in four parts, with from left to right an incomebased segmentation and from top to bottom an energy use intensity-based segmentation. First, as we saw that fuel poverty was mainly income poverty in disguise, income is the main driver for energy policies market segmentation. Households with enough revenue to engage energy efficiency investments are said to be "in the market" and will be sensitive to market-based incentives (fiscal tax or cuts, or investments nudges) to trigger energy savings or energy 
efficiency investments. Households with revenue below median (and among them the fuel poor that earn less than $60 \%$ of the median income) cannot afford energy efficiency investments on their homes and are therefore more sensitive to "off market" policy measures such as social benefits, revenue transfers and facility payments. Households' groups "in the market" are located on the right quadrant, and "off market" households' groups are located on the left quadrant. Second, the market can be divided vertically given each households' group's energy use intensity. Household groups are located top or bottom whether their annual energy expenditures are respectively above or below median for a given housing type. This segmentation is helpful to visually identify potential rebound or backfire effects from household groups that have a low intensity score. In other words, if a household spends twice as less annually than the median household, then it is more likely that the household will use a significant part of the extra revenue from energy efficiency to consume more energy service to meet its comfort basic needs.

Figure 2. Houses market mapping



Source: Authors' calculations. 
First of all, our findings show that group segmentation and sizing differ given the dwelling type. Household groups have relatively homogeneous sizes, and smooth but strong income elasticity. On the one hand, a fair proportion in population size (close to $60 \%$ of households living in houses) is located on the right quadrant which makes them good candidates for "market" energy policy incentives. On the other hand, four groups are located on the bottom right of the quadrant, which makes them strong rebound or backfire effect candidates. Surprisingly, those are not the fuel poor group we previously portrayed, and most of them are electric-heated households who face double capital constraint on energy use and equipment. They might have a strong rebound effect as they sacrifice a lot of their comfort to accommodate their budget constraint and therefore consume less than the fuel poor groups.

Figure 3. Flat market mapping

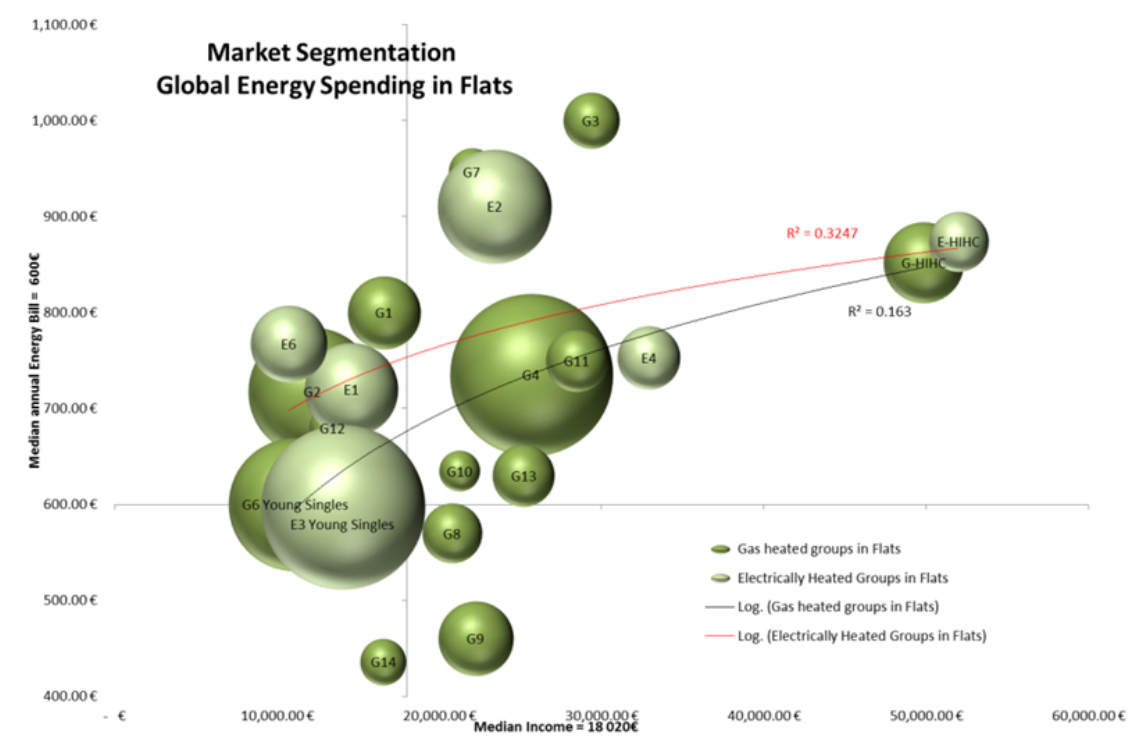

Source: Authors' calculations.

Energy expenditures in flats are driven by other factors than income, such as construction date and dwelling characteristics. In that case, energy policy measures that use dwelling or standards of living-based incentives should be more welcome than pure income incentives.

High consumption and high income household groups located top right of the market quadrant in Figures 2 and 3 can enjoy a windfall effect on the energy efficiency market as they can 
benefit from subsidies and tax cuts, whereas they already are "in the market" with a strong probability that they could benefit from energy efficiency investments without the help of such public measures. In fact, Charlier (2015) recently discovered that among the fifth decile households, this "dead-weight loss" effect could concern most of the energy efficiency investments on the French residential market. Keeping in mind that the income effect is much stronger in houses (Figure 2) than in flats (Figure 3), households with electric-heated houses are more income sensitive (higher elasticity) than gas-heated houses (Figure 2), making them more sensible to a free-rider rebound effect.

\subsection{Energy efficiency distortion score}

Nonlinear group analysis is an approach that allows for operational tools such as a scoring analysis that reduces uncertainty about the gap between predicted and real consumptions. Distortion score is a useful tool for financial and insurance mechanism when energy efficiency investments involve more than one economic agent and is subject to information asymmetries and moral hazard. The score can be used for energy efficiency financing contracts based on retrofits cash-flows as it minimizes the outcome interval and reduces information asymmetry between the energy consumer, the investor and the financing agent. ${ }^{14}$

The energy efficiency distortion score is a synthesis of two effects: intensity and revenue, calculated on homogenously distributed households. Relative to the two median groups in houses and flats, half of the groups are expected to have a positive rebound effect on energy efficiency measures (19 groups), and the other half is expected to embrace energy efficiency measures on their homes with positive attitude or even windfall behavior such as HIHC households' groups especially in flats.

\footnotetext{
${ }^{14}$ See Appendix 7.3 for further details on the score construction.
} 
Figure 4: Energy efficiency distortion score

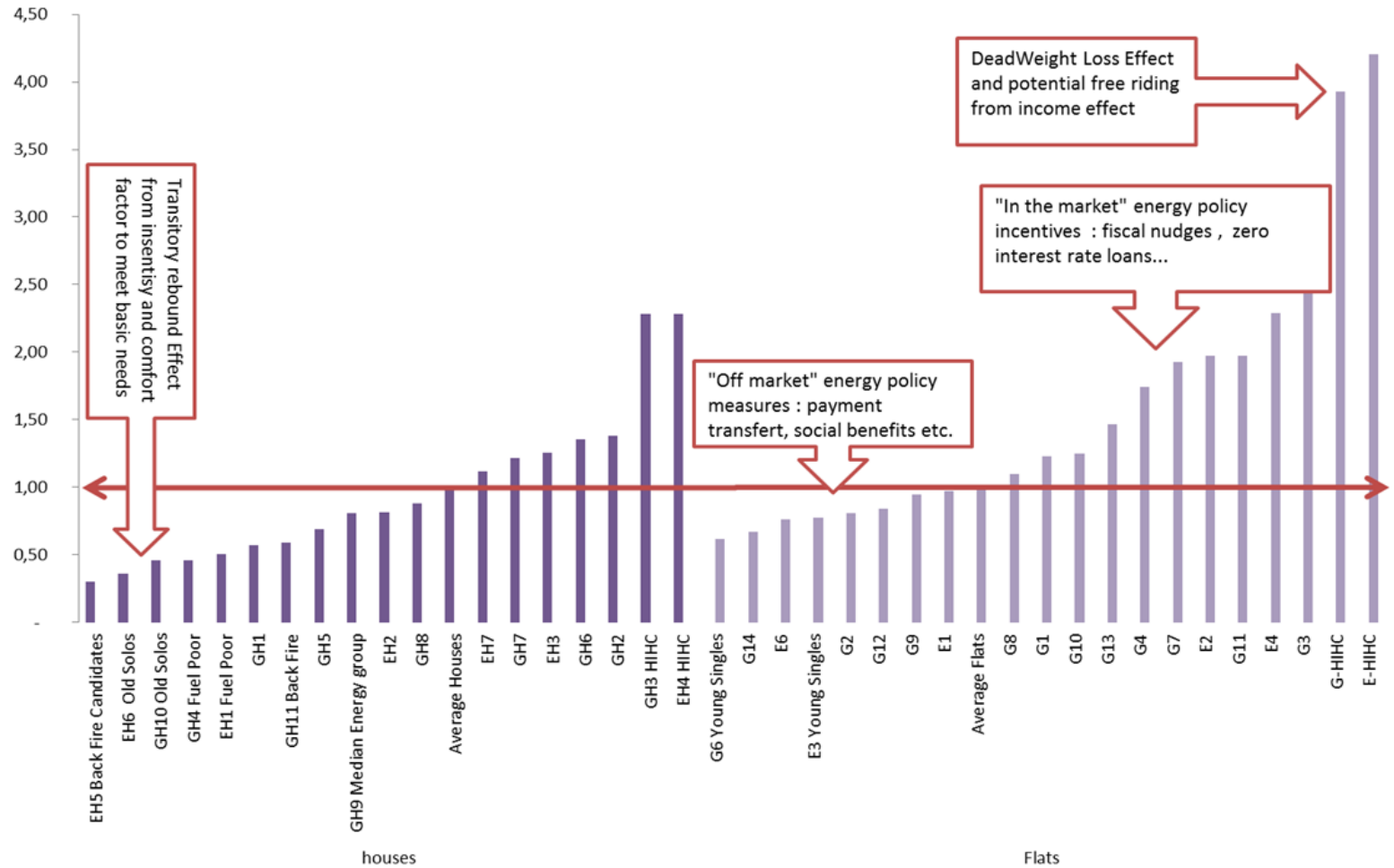

Source: Authors' calculations.

The resulting score is slightly S-shaped (see Figure 4) and reflects the evolution of income and intensity elasticity as household revenues get bigger. For very low scores, the distortion effect is below unity and indicates that households are likely to use an additional budget to meet their "comfort" energy needs that were previously unfulfilled due to a biding budget constraint (for example by setting an acceptable level of warmth). Therefore, energy efficiency measures will first exhibit a rebound effect, but will improve and harmonize living conditions among households as well as developing energy efficient behaviors. The distortion score then gets closer to one until it reaches median household groups and increases greatly above unity for the following groups. High distortion score reflects high leverage for energy efficiency markets, but very high score can also be the sign of windfall effect and free riding that overall can offset energy efficiency revenue incentives. High distortion score households can enjoy the extra energy efficiency revenue to meet energy luxury needs according to 
bigger income elasticity. For example, households can use energy subsidies to change an old heat pump and replace it with a bigger new one.

\section{Conclusion and policy recommendations}

The aim of this paper is to provide a disaggregated-level analysis to investigate heterogeneity in French households' energy consumption. Using a clustering method based on the CHAID methodology, we show that the main identified drivers for energy consumption are related to the house's characteristics: heating fuel or equipment type, dwelling type and size, and construction date. Whereas income is crucial in determining the level of energy consumed, other households' characteristics also play a significant role: the location choice (urban density), the family type and the tenure (for electricity) are significant factors that have to be accounted for when estimating households' energy consumption. On the contrary, we find no significant evidence of learning effect through seniority influence for energy consumptionage or seniority being non-significant. Access to gas is a key to lower electricity bill, but it does not prevent from fuel vulnerability or even poverty in the case of very poor and constrained households as we found fuel poverty cases among gas-heated households in houses.

Fuel poverty is first and foremost a pendant of poverty itself. Our results show that it is more driven by revenue than dwelling characteristics and/or energy consumption habits. Poor households face a double constraint on (i) the level and price of energy use, and (ii) the quality and type of the heating equipment as they are less likely to access to cheaper fuel prices, energy efficient homes and infrastructures. First, low income households are more likely to fall into fuel poverty than richer households because they spend a significantly higher share of their income on house energy than richer households. Second, they have lower ability and willingness to engage in the energy market (switch supplier tariffs): whereas poor households are well known to play a great role as savvy customers in the food market, they have less access to the energy market and do not drive up supplier competition (Preston et al., 2014). Third, fuel poor groups are over-represented in northern France where the climate is more rigorous, and they are more likely living in big but old houses in rural areas: as such, 
they are less likely to have access to gas and transport infrastructures of high density living areas that are identified factors of lower energy bills.

The change in household energy consumption is a complex and microeconomic process depending on a range of factors that are related to three types: dwelling characteristics, household characteristics and exogenous factors. Energy policy measures that target a single energy consumption level can only be arbitrary and will exhibit mixed results if they are modeled from technical characteristics or even the average household behavior. If we follow the hypothesis that income elasticity path is S-shaped and differs with diverse levels of income reflecting different natures of energy needs and arbitrages, then disaggregated policy measures targeted on household groups is a fair method to take those differences into account and prevent energy related inequalities to linger or grow.

Specifically, our group classification approach sheds the light on the energy divide among households and the fact that energy efficiency programs must be implemented carefully as the uncertain rebound effect can take two origins. The first rebound effect stems from the lowest revenue households with a low intensity factor, and results from the newly unbinding budget constraint and the desire to meet basic energy needs. This rebound effect has to be accounted for but is also likely to be (i) transitory (when fuel poor or vulnerable households all satisfy their basic energy needs, they will use their extra income for something else), and (ii) desirable as the housing stock grows towards more energy equity but also towards more energy performance. The second, at the other end of the energy efficiency distortion score, is the case of very high income households that can use energy efficiency revenue incentives as free riders in order to meet more energy luxury needs. This rebound effect is far less desirable as it consumes public spending in the case of revenue-based incentives (tax cuts or straight monetary subventions) and increases the energy gap between households although the benefit related to energy performance of the housing stock is fair.

Our distortion score suggests that energy policy measures need to take income and other differences among households into consideration as consumers' response to changes in income and energy prices will differ according to their initial score and take peculiar attention to the extreme score values. Different instruments dedicated to specific household groups would probably be a more efficient strategy to overcome the increasing energy divide among 
households. For low score groups and fuel poor households, "off market" measures such as transfer payments and social benefits are more suited to help households improve their level of warmth and appliance usage in the most energy efficient way. On the contrary, where revenue incentives can generate free riding among high distortion score households, patrimonial incentives that integrate the energy performance into the house patrimonial "green value" appear to be an efficient way to trigger energy efficiency investment with no windfall or free-riding effect. 


\section{Bibliography}

Baker, P., Blundell, R., 1991. The Microeconometric Approach to Modelling Energy Demand: Some Results for UK Households. Oxford Review of Economic Policy 7(2), 5476.

Baker, P., Blundell, R., Micklewright, J., 1989. Modelling Household Energy Expenditures Using Micro-data. Economic Journal 99(397), 720-38.

Belson, W.A., 1959. Matching and Prediction on the Principle of Biological Classification. Journal of the Royal Statistical Society, Series C (Applied Statistics) 8.2, 65-75.

Blundell, R., Kristensen, D., Matzkin, R., 2014. Bounding quantile demand functions using revealed preference inequalities. Journal of Econometrics 179, 112-127.

Braun, F.G., 2010. Determinants of households' space heating type: A discrete choice analysis for German households. Energy Policy 38, 5493-5503.

Cavailhès, J., Joly, D., Brossard, T., Cardot, H., Hilal, M., Wavresky, P., 2011. Consommation d'énergie des ménages en France. Report, INRA and CNRS.

Cayla, J.-M., Allibe, B., Laurent, M.-H., 2010. From Practices to Behaviors: Estimating the Impact of Household Behavior on Space Heating Energy Consumption. In ACEEE Summer Study on Energy Efficiency in Buildings. Pacific Grove, CA, United States. https://hal-mines-paristech.archives-ouvertes.fr/hal-00509187.

Cayla, J.-M., Maizi, N., Marchand, C., 2011. The role of income in energy consumption behaviour: Evidence from French households data. Energy Policy 39, 7874-7883. doi:10.1016/j.enpol.2011.09.036

Charlier, D. 2015. Energy Efficiency Investments in the Context of Split Incentives among French Households. Energy Policy 87 (C), 465-79.

DECC, 2009. Annual Report on Fuel Poverty Statistics 2009. Department for Energy and Cli mate Change. Available at: http://www.decc.gov.uk.

Devalière, I., Briant, P., Arnault, S. 2011. La précarité énergétique : avoir froid ou dépenser trop pour se chauffer. INSEE Première, May, $\mathrm{n}^{\circ} 1351$. Doyle, P., 1973. The use of automatic interaction detector and similar search procedures. Operational Research Quarterly 24(3), 465-467. 
Druckman, 2011. Missing carbon reductions? Exploring rebound and backfire effects in UK households. Energy Policy 39, 3572-3581.

Druckman, A., Jackson, T., 2008. Household energy consumption in the UK: A highly geographically and socio-economically disaggregated model. Energy Policy 36, 31773192. doi:10.1016/j.enpol.2008.03.021

Dubin, J., Miedema, A., Chandran, R., 1986. Price Effects of Energy-Efficient Technologies: A Study of Residential Demand for Heating and Cooling. Rand Journal of Economics17(3), 310-325.

Greening, A.L., Greene, D.L., Difiglio, C., 2000. Energy efficiency and consumption - the rebound effect — a survey. Energy Policy 28, 389-401. doi:10.1016/S03014215(00)00021-5

Guerra Santin, O., Itard, L., Visscher, H., 2009. The effect of occupancy and building characteristics on energy use for space and water heating in Dutch residential stock. Energy and Buildings 41, 1223-1232. doi:10.1016/j.enbuild.2009.07.002

Haas, R., Biermayr, P., 2000. The rebound effect for space heating Empirical evidence from Austria. Energy Policy 28(6-7), 403-410.

Hassett, K.A., Metcalf, G.E., 1993. Energy conservation investment: Do consumers discount the future correctly? Energy Policy 21, 710-716. doi:10.1016/0301-4215(93)90294-P

Haughton, D., Oulabi, S., 1993. Direct marketing modeling with CART and CHAID. Journal of Direct Marketing 7, 16-26.

Hausman, J.A., 1979. Individual Discount Rates and the Purchase and Utilization of EnergyUsing Durables. The Bell Journal of Economics 10, 33. doi:10.2307/3003318

Hills, J., 2012. Getting the measure of fuel poverty: final report of the Fuel Poverty Review.

Jamasb, T., Meier, H., 2010. Household Energy Expenditure and Income Groups: Evidence from Great Britain. Cambridge Working Papers in Economics 1011, Faculty of Economics, University of Cambridge.

Jamasb, T., Meier, H., 2011. Energy spending and vulnerable households. Cambridge Working Papers in Economics, Faculty of Economics, University of Cambridge. 
Kass, G.V., 1980. An exploratory technique for investigating large quantities of categorical data. Applied Statistics 29(2), 119-127.

Khazzoom, J.D., 1980. Economic Implications of Mandated Efficiency in Standards for Household Appliances. The Energy Journal 1, 21-40.

McCarty, J.A., Hastak, M., 2007. Segmentation approaches in data-mining: A comparison of RFM, CHAID, and logistic regression. Journal of Business Research, Consumer Personality and Individual Differences 60, 656-662. doi:10.1016/j.jbusres.2006.06.015

Meier, H., Jamasb, T., Orea, L., 2013. Necessity or Luxury Good? Household Energy Spending and Income in Britain 1991-2007. Energy Journal 34 (4), 109-128.

Meier, H., Rehdanz, K., 2010. Determinants of residential space heating expenditures in Great Britain. Energy Economics 32, 949-959. doi:10.1016/j.eneco.2009.11.008

Messenger, R., Mandell, L. 1972. A modal search technique for predictive nominal scale multivariate analysis. Journal of the American Statistical Association 67(340), 768-772.

Morgan, J.N., Messenger, R.C., 1973. THAID a sequential analysis program for analysis of nominal scale dependent variables. Ann Arbor, Survey Research Center, Institute for Social Research, University of Michigan.

Morgan, J.N., Sonquist, J.A., 1963. Problems in the analysis of survey data, and a proposal. Journal of the American Statistical Association 58, 415-435.

Nesbakken, R., 2001. Energy Consumption for Space Heating: A Discrete-Continuous Approach. The Scandinavian Journal of Economics 103, 165-184.

Parti, M., Parti, C., 1980. The Total and Appliance-Specific Conditional Demand for Electricity in the Household Sector. The Bell Journal of Economics 11, 309. doi: $10.2307 / 3003415$

Preston, I., White, V., Katharine, B., Hirsh, D., 2014. Fuel Poverty. A Rapid Evidence Assessment for the Joseph Rowntree Foundation. Centre for Sustainable Energy. Reg charity 298740, Bristol, UK.

Rehdanz, K., 2007. Determinants of residential space heating expenditures in Germany. Energy Economics 29, 167-182. doi:10.1016/j.eneco.2006.04.002 
Ritschard, G., 2010. CHAID and Earlier Supervised Tree Methods. Research Papers 2010.02, Institute of Economics and Econometrics, Geneva School of Economics and Management, University of Geneva.

Roberts, D., Vera-Toscano, E., Phimister, E., 2015. Fuel poverty in the UK: Is there a difference between rural and urban areas? Energy Policy 87, 216-223.

Sonderegger, R.C., 1977. Movers and stayers: the resident's contribution to variation across houses in energy consumption for space heating. Energy and Buildings 1, 313-324.

Sorrell, S., Dimitropoulos, J., 2008. The rebound effect: Microeconomic definitions, limitations and extensions. Ecological Economics 65, 636-649. doi:10.1016/j.ecolecon.2007.08.013

Thomson, H., Snell, C., 2013. Quantifying the prevalence of fuel poverty across the European Union. Energy Policy, Special Section: Transition Pathways to a Low Carbon Economy 52, 563-572. doi:10.1016/j.enpol.2012.10.009

Vaage, K., 2000. Heating Technology and Energy Use: a Discrete/Continuous Choice Approach to Norwegian Household Energy Demand. Department of Economics, University of Bergen No. 214.

Van Diepen, M., Franses, P.H., 2006. Evaluating chi-squared automatic interaction detection. Information Systems 31, 814-831. doi:10.1016/j.is.2005.03.002

Vickers, D., Rees, P., 2007. Creating the UK National Statistics 2001 output area classification. Journal of the Royal Statistical Society: Series A (Statistics in Society) $170,379-403$.

Wyatt, P., 2013. A dwelling-level investigation into the physical and socio-economic drivers of domestic energy consumption in England. Energy Policy 60, 540-549. doi:10.1016/j.enpol.2013.05.037 


\section{Appendix}

\subsection{French households' energy consumption and budget share regarding housing and households' characteristics}

\begin{tabular}{|c|c|c|c|c|c|c|}
\hline & $\begin{array}{c}\text { Annual } \\
\text { Energy } \\
\text { Expenditures }\end{array}$ & $\begin{array}{c}\text { Energy } \\
\text { Budget } \\
\text { Share } \\
(\%)\end{array}$ & $\begin{array}{c}\text { Annual } \\
\text { Energy } \\
\text { Expenditures }\end{array}$ & $\begin{array}{c}\text { Energy } \\
\text { Budget } \\
\text { Share } \\
(\%)\end{array}$ & $\begin{array}{c}\text { Annual } \\
\text { Energy } \\
\text { Expenditures }\end{array}$ & $\begin{array}{c}\text { Energy } \\
\text { Budget } \\
\text { Share } \\
(\%)\end{array}$ \\
\hline Year of Construction & \multicolumn{2}{|c|}{ Average } & \multicolumn{2}{|c|}{ Electricity heated } & \multicolumn{2}{|c|}{ Gas heated } \\
\hline Before 1871 & $1364 €$ & 5.84 & $1423 €$ & 6.1 & $1288 €$ & 4.9 \\
\hline 1871-1914 & $1077 €$ & 5.34 & $1100 €$ & 3.5 & $1066 €$ & 4.7 \\
\hline $1915-1948$ & $1015 €$ & 5.17 & $1092 €$ & 5.9 & $1000 €$ & 4.7 \\
\hline $1949-1961$ & $784 €$ & 4.07 & $1039 €$ & 6.0 & $700 €$ & 3.8 \\
\hline $1962-1967$ & $650 €$ & 3.64 & $1200 €$ & 5.8 & $600 €$ & 3.4 \\
\hline 1968-1974 & $612 €$ & 3.41 & $1171 €$ & 5.3 & $544 €$ & 3.1 \\
\hline $1975-1981$ & $900 €$ & 3.62 & $1258 €$ & 4.7 & $688 €$ & 3.3 \\
\hline 1982-1989 & $978 €$ & 3.62 & $1240 €$ & 4.2 & $730 €$ & 3.3 \\
\hline 1990-1998 & $850 €$ & 3.59 & $1225 €$ & 3.9 & $713 €$ & 3.4 \\
\hline 1999 and after & $988 €$ & 3.28 & $1092 €$ & 3.7 & $858 €$ & 3.1 \\
\hline Occupation Status & \multicolumn{2}{|c|}{ Average } & \multicolumn{2}{|c|}{ Electricity heated } & \multicolumn{2}{|c|}{ Gas heated } \\
\hline New Owner & $1250 €$ & 3.40 & $1375 €$ & 3.8 & $1133 €$ & 3.0 \\
\hline Tenants & $617 €$ & 3.78 & $700 €$ & 4.4 & $600 €$ & 3.6 \\
\hline Landlords & $1163 €$ & 4.38 & $1498 €$ & 5.2 & $900 €$ & 3.8 \\
\hline Revenue Decile & \multicolumn{2}{|c|}{ Average } & \multicolumn{2}{|c|}{ Electricity heated } & \multicolumn{2}{|c|}{ Gas heated } \\
\hline 1 & $635 €$ & 9.99 & $680 €$ & 11.0 & $600 €$ & 9,3 \\
\hline 2 & $720 €$ & 6.47 & $843 €$ & 7.6 & $645 €$ & 5,8 \\
\hline 3 & $739 €$ & 5.06 & $890 €$ & 6.1 & $660 €$ & 4,4 \\
\hline 4 & $825 €$ & 4.53 & $990 €$ & 5.4 & $710 €$ & 3,9 \\
\hline 5 & $900 €$ & 4.11 & $1130 €$ & 5.0 & $780 €$ & 3,5 \\
\hline 6 & $1049 €$ & 3.94 & $1213 €$ & 4.6 & $915 €$ & 3.5 \\
\hline 7 & $1100 €$ & 3.47 & $1262 €$ & 4.0 & $980 €$ & 3.0 \\
\hline 8 & $1220 €$ & 3.20 & $1337 €$ & 3.5 & $1100 €$ & 2.9 \\
\hline 9 & $1301 €$ & 2.79 & $1496 €$ & 3.1 & $1164 €$ & 2.5 \\
\hline 10 & $1500 €$ & 2.03 & $1680 €$ & 2.3 & $1380 €$ & 1.9 \\
\hline \multicolumn{7}{|l|}{ Family Type } \\
\hline Couple with children & $1090 €$ & 3.3 & $1300 €$ & $3.7 \%$ & $930 €$ & 3.08 \\
\hline Couple without children & $1040 €$ & 3.5 & $1245 €$ & $4.0 \%$ & $890 €$ & 3.14 \\
\hline Single Person & $641 €$ & 5.0 & $750 €$ & $5.6 \%$ & $585 €$ & 4.63 \\
\hline
\end{tabular}




\begin{tabular}{|c|c|c|c|c|c|c|}
\hline $\begin{array}{c}\text { Single Wo-Man with Children } \\
\text { Unrelated people living together }\end{array}$ & $730 €$ & 5.2 & $900 €$ & $5.9 \%$ & $680 €$ & 4.92 \\
& $779 €$ & 3.8 & $1106 €$ & $4.5 \%$ & $684 €$ & 3.55 \\
\hline Urban Density & $1340 €$ & 4.6 & $1350 €$ & $4.7 \%$ & $1282 €$ & 4.19 \\
\hline $\begin{array}{c}\text { Rural area } \\
\text { Low density } \\
\text { (<20k hab) } \\
\text { Medium density } \\
\text { (20k-200 k hab) } \\
\text { High density } \\
\text { (200k-2M hab) } \\
\text { Paris }\end{array}$ & $1076 €$ & 4.5 & $1260 €$ & $4.7 \%$ & $900 €$ & 4.20 \\
\hline Total (Average) & $730 €$ & 3.8 & $1048 €$ & $4.2 \%$ & $680 €$ & 3.75 \\
\hline
\end{tabular}




\subsection{CHAID algorithm}

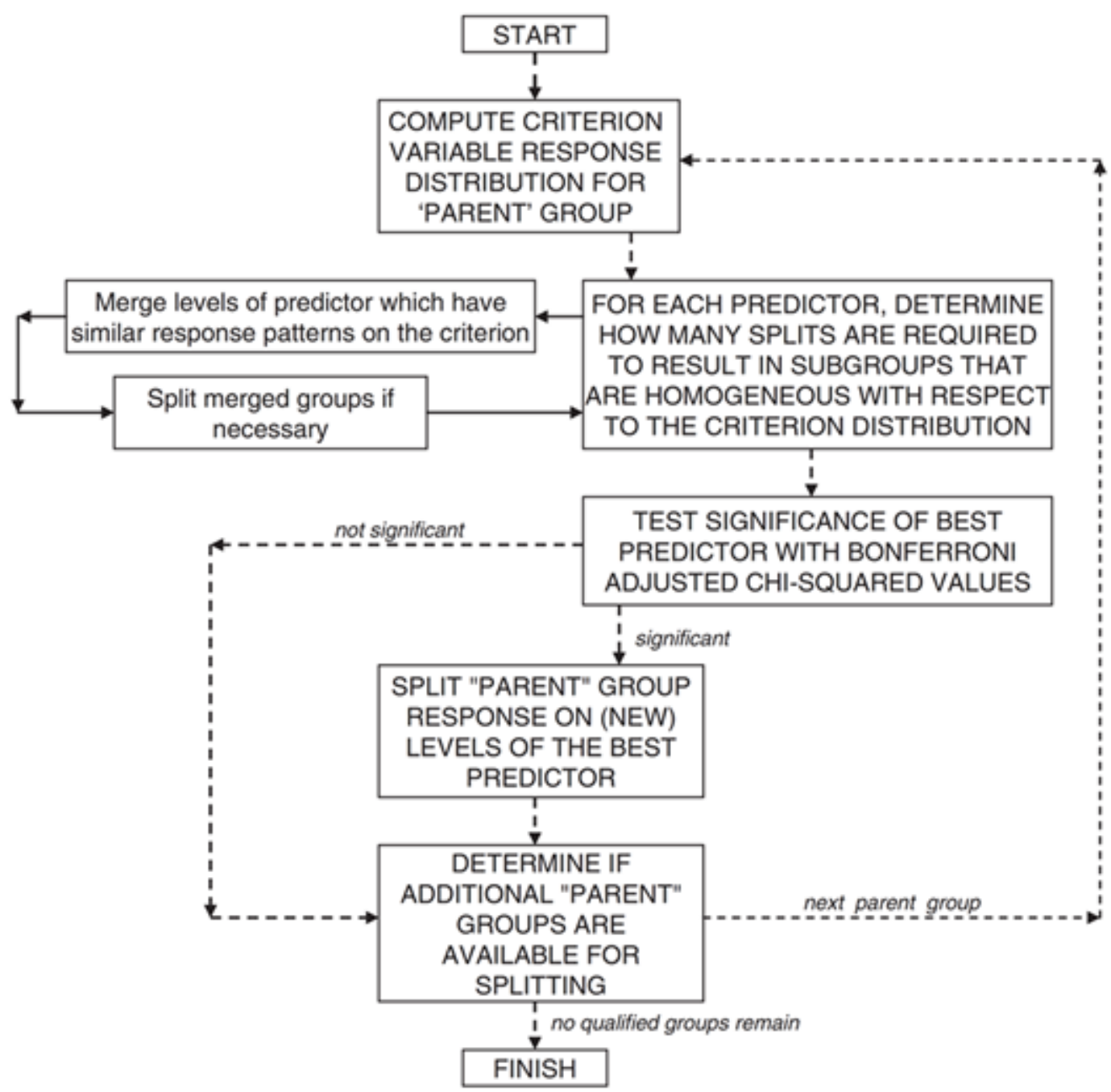

7.3. Market mapping and distortion score

7.3.1. Households living in houses

\begin{tabular}{|c|c|c|c|c|c|c|c|c|}
\hline $\begin{array}{c}\text { Houses } \\
\text { Stock }\end{array}$ & Groups & Median & Weight & $\begin{array}{c}\text { Median } \\
\text { Global } \\
\text { Energy }\end{array}$ & $\begin{array}{c}\text { Energy } \\
\text { Budget } \\
\text { Share }\end{array}$ & $\begin{array}{c}\text { Intensit } \\
\text { factor }\end{array}$ & $\begin{array}{c}\text { Income/medi } \\
\text { an }\end{array}$ & $\begin{array}{c}\text { Efficiency } \\
\text { Distortion } \\
\text { Score }\end{array}$ \\
\hline
\end{tabular}




\begin{tabular}{|c|c|c|c|c|c|c|c|c|}
\hline \multirow{11}{*}{ 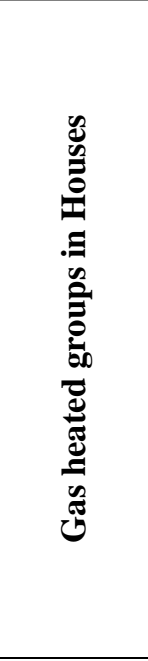 } & GH1 & $15882 €$ & $2.6 \%$ & $1200 €$ & $7.90 \%$ & 1.00 & 0.57 & 0.57 \\
\hline & $\mathrm{GH} 2$ & $33203 €$ & $5.7 \%$ & $1382 €$ & $4.13 \%$ & 1.15 & 1.20 & 1.38 \\
\hline & GH3 HIHC & $52697 €$ & $17.9 \%$ & $1440 €$ & $2.57 \%$ & 1.20 & 1.90 & 2.28 \\
\hline & $\begin{array}{l}\text { GH4 Fuel } \\
\text { Poor }\end{array}$ & $12811 €$ & $7.3 \%$ & $1191 €$ & $9.71 \%$ & 0.99 & 0.46 & 0.46 \\
\hline & GH5 & $19673 €$ & $2.2 \%$ & $1170 €$ & $6.21 \%$ & 0.98 & 0.71 & 0.69 \\
\hline & GH6 & $33183 €$ & $1.7 \%$ & $1356 €$ & $4.12 \%$ & 1.13 & 1.20 & 1.35 \\
\hline & GH7 & $33778 €$ & $7.2 \%$ & $1200 €$ & $3.56 \%$ & 1.00 & 1.22 & 1.22 \\
\hline & GH8 & $23088 €$ & $5.1 \%$ & $1265 €$ & $5.58 \%$ & 1.05 & 0.83 & 0.88 \\
\hline & GH9 & $22393 €$ & $2.3 \%$ & $1200 €$ & $5.56 \%$ & 1.00 & 0.81 & 0.81 \\
\hline & $\begin{array}{l}\text { GH10 Old } \\
\text { Solos }\end{array}$ & $15296 €$ & $1.7 \%$ & $997 €$ & $6.39 \%$ & 0.83 & 0.55 & 0.46 \\
\hline & $\begin{array}{c}\text { GH11 Back } \\
\text { Fire }\end{array}$ & $19660 €$ & $1.0 \%$ & $1000 €$ & $4.94 \%$ & 0.83 & 0.71 & 0.59 \\
\hline \multirow{7}{*}{ 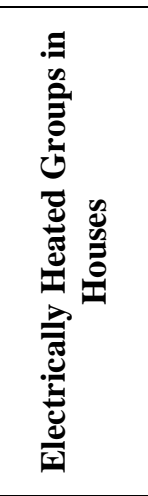 } & $\begin{array}{l}\text { EH1 Fuel } \\
\text { Poor }\end{array}$ & $14052 €$ & $3.2 \%$ & $1200 €$ & $9.47 \%$ & 1.00 & 0.51 & 0.51 \\
\hline & EH2 & $22999 €$ & $8.7 \%$ & $1180 €$ & $5.09 \%$ & 0.98 & 0.83 & 0.82 \\
\hline & EH3 & $33309 €$ & $10.6 \%$ & $1250 €$ & $3.77 \%$ & 1.04 & 1.20 & 1.25 \\
\hline & EH4 HIHC & $51168 €$ & $13.3 \%$ & $1485 €$ & $2.71 \%$ & 1.24 & 1.85 & 2.28 \\
\hline & $\begin{array}{c}\text { EH5 Back } \\
\text { Fire } \\
\text { Candidates }\end{array}$ & $11674 €$ & $3.0 \%$ & $861 €$ & $8.06 \%$ & 0.72 & 0.42 & 0.30 \\
\hline & $\begin{array}{l}\text { EH6 Old } \\
\text { Solos }\end{array}$ & $12000 €$ & $4.4 \%$ & $994 €$ & $8.44 \%$ & 0.83 & 0.43 & 0.36 \\
\hline & EH7 & $33279 €$ & $2.0 \%$ & $1119 €$ & $3.39 \%$ & 0.93 & 1.20 & 1.12 \\
\hline $\begin{array}{c}\text { Average } \\
\text { Houses }\end{array}$ & & $27720 €$ & $100.00 \%$ & $1200 €$ & $4.25 \%$ & 1.00 & 1.00 & 1.00 \\
\hline
\end{tabular}

7.3.2. Households living in flats

\begin{tabular}{|c|c|c|c|c|c|c|c|c|}
\hline $\begin{array}{l}\text { Individual } \\
\text { Dwelling } \\
\text { stock }\end{array}$ & Groups & $\begin{array}{l}\text { Median } \\
\text { Income }\end{array}$ & Weight & $\begin{array}{l}\text { Median } \\
\text { Global } \\
\text { Energy } \\
\text { Bill } \\
\end{array}$ & $\begin{array}{l}\text { Energy } \\
\text { Budget } \\
\text { Share }\end{array}$ & $\begin{array}{l}\text { Intensity } \\
\text { factor }\end{array}$ & $\begin{array}{l}\text { Income/med } \\
\text { ian }\end{array}$ & $\begin{array}{c}\text { Energy Efficiency } \\
\text { Distortion Score }\end{array}$ \\
\hline \multirow{9}{*}{ 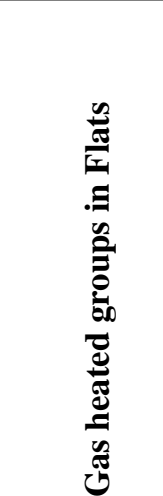 } & G1 & $16595 €$ & $3.3 \%$ & $800 €$ & $4.34 \%$ & 1.33 & 0.92 & 1.23 \\
\hline & G2 & $12191 €$ & $10.2 \%$ & $718 €$ & $6.32 \%$ & 1.20 & 0.68 & 0.81 \\
\hline & G3 & $29354 €$ & $1.9 \%$ & $1000 €$ & $2.97 \%$ & 1.67 & 1.63 & 2.71 \\
\hline & G4 & $25673 €$ & $16.3 \%$ & $735 €$ & $2.81 \%$ & 1.23 & 1.42 & 1.75 \\
\hline & G-HIHC & $49845 €$ & $4.0 \%$ & $852 €$ & $1.66 \%$ & 1.42 & 2.77 & 3.93 \\
\hline & $\begin{array}{l}\text { G6 Young } \\
\text { Singles }\end{array}$ & $11101 €$ & $10.8 \%$ & $600 €$ & $5.57 \%$ & 1.00 & 0.62 & 0.62 \\
\hline & G7 & $22025 €$ & $1.4 \%$ & $947 €$ & $4.18 \%$ & 1.58 & 1.22 & 1.93 \\
\hline & G8 & $20800 €$ & $2.2 \%$ & $570 €$ & $2.63 \%$ & 0.95 & 1.15 & 1.10 \\
\hline & G9 & $22258 €$ & $3.4 \%$ & $461 €$ & $2.11 \%$ & 0.77 & 1.24 & 0.95 \\
\hline
\end{tabular}




\begin{tabular}{|c|c|c|c|c|c|c|c|c|}
\hline & $\begin{array}{l}\text { G10 } \\
\text { G11 } \\
\text { G12 } \\
\text { G13 } \\
\text { G14 }\end{array}$ & $\begin{array}{l}21240 € \\
28463 € \\
13410 € \\
25194 € \\
16545 €\end{array}$ & $\begin{array}{l}1.0 \% \\
2.4 \% \\
1.3 \% \\
2.3 \% \\
1.3 \%\end{array}$ & $\begin{array}{l}635 € \\
750 € \\
680 € \\
630 € \\
436 €\end{array}$ & $\begin{array}{l}3.04 \% \\
2.61 \% \\
4.81 \% \\
2.65 \% \\
3.14 \%\end{array}$ & $\begin{array}{l}1.06 \\
1.25 \\
1.13 \\
1.05 \\
0.73\end{array}$ & $\begin{array}{l}1.18 \\
1.58 \\
0.74 \\
1.40 \\
0.92\end{array}$ & $\begin{array}{l}1.25 \\
1.97 \\
0.84 \\
1.47 \\
0.67\end{array}$ \\
\hline 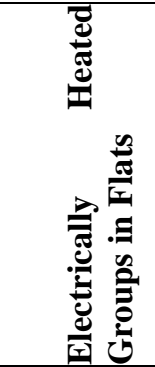 & $\begin{array}{l}\text { E1 } \\
\text { E2 } \\
\text { E3 - Young } \\
\text { Singles } \\
\text { E4 } \\
\text { E-HIHC } \\
\text { E6 } \\
\end{array}$ & $\begin{array}{l}14563 € \\
23409 € \\
14055 € \\
32900 € \\
52000 € \\
10716 €\end{array}$ & $\begin{array}{l}5.4 \% \\
7.9 \% \\
16.7 \% \\
2.4 \% \\
2.2 \% \\
3.5 \% \\
\end{array}$ & $\begin{array}{l}720 € \\
911 € \\
598 € \\
753 € \\
874 € \\
768 €\end{array}$ & $\begin{array}{l}5.16 \% \\
3.80 \% \\
4.32 \% \\
2.29 \% \\
1.56 \% \\
6.57 \% \\
\end{array}$ & $\begin{array}{l}1.20 \\
1.52 \\
1.00 \\
1.26 \\
1.46 \\
1.28 \\
\end{array}$ & $\begin{array}{l}0.81 \\
1.30 \\
0.78 \\
1.83 \\
2.89 \\
0.59 \\
\end{array}$ & $\begin{array}{l}0.97 \\
1.97 \\
0.78 \\
2.29 \\
4.20 \\
0.76 \\
\end{array}$ \\
\hline $\begin{array}{l}\text { Average } \\
\text { Flats }\end{array}$ & & $18020 €$ & $100.00 \%$ & $600 €$ & $3.33 \%$ & 1.00 & 1.00 & 1.00 \\
\hline
\end{tabular}

